\title{
Synthesis and Investigations on Antioxidant Behaviour of Chromone based Semicarbazones
}

\author{
GURPINDER SINGH* and KRITIKA THAKUR \\ Department of Chemistry, Lovely Professional University, Phagwara, 144411, India. \\ ${ }^{*}$ Corresponding author E-mail: gurpinder.singh @ Ipu.co.in
}

http://dx.doi.org/10.13005/ojc/340653

(Received: August 01, 2018; Accepted: October 21, 2018)

\begin{abstract}
Chromone derived carbazones provide an important antioxidant activity by exhibiting radical scavenging action, Semicarbazones are synthesized in good yield and these act as a good radical scavenger, where the presence of various substituent at C-6 of chromone nucleus tend to alter the activity behaviour, presence of electronegative atom such as fluoro/ chloro enhances the radical scavenging activity in comparison to electron donating group.
\end{abstract}

Keywords: Chromone, Antioxidant, DPPH, Radical scavenging.

INTRODUCTION

Chromone (1) has been recognized as one of the most versatile moieties ${ }^{1}$, which constitutes the basic nucleus of one of the most numerous and widespread group of natural products called 'Flavonoids' and these not only contribute to the colours of the plant kingdom but a large number of them display valuable biological activities, and many are known as therapeutics².

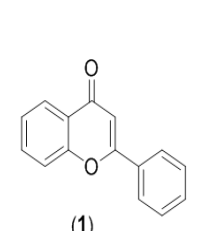

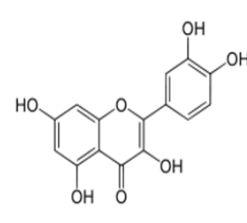

(2)

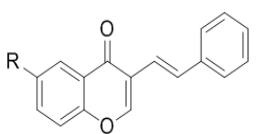

(3)
Chromone i.e., benzopyran-4-one (1) has also emerged as essential component of the pharmacophore of a large number of biologically active compounds of synthetic origin and biological activities are continuously being discovered in naturally occurring and synthetic chromone derivatives, some of the significant bioactivities among the chromone derivatives include antioxidants ${ }^{3}$, HIV-inhibitory ${ }^{4}$, antimalarial ${ }^{5}$, antiviral $^{6}$, antigiardial ${ }^{7}$, cytotoxic $^{8}$, phosphoinositide3-kinase inhibitor ${ }^{9}$, protein tyrosine kinase inihibitor ${ }^{10}$, anti-erectile-dysfunction ${ }^{11}$, anti-inflammatory ${ }^{12}$, mono-amine-oxidase inhibitor ${ }^{13}$, adenosine receptor antagonists ${ }^{14}$, antiplatelet ${ }^{15}$, anti-fungal ${ }^{16}$, selective estrogen receptor modulator ${ }^{17}$, anti-tumor/antiproliferative ${ }^{18}$, anti-psychotic ${ }^{19}$, neuroprotective ${ }^{20}$ and P-glycoprotein modulator ${ }^{21}$.

The antioxidants have recently gained a lot of interest due to their active involvement

This is an Open Access article licensed under a Creative Commons license: Attribution 4.0 International (CC- BY). Published by Oriental Scientific Publishing Company @ 2018 
as prophylactic and therapeutic agents in many diseases ${ }^{2}$. A lot of naturally occurring flavonoids have played a significant role in the study of antioxidant behaviour indicating the importance of these class of compounds in the control of oxidative stress and damage to the living system. A lot of effort have been centred around to check the action of free radical generated in the biological system which not only lead to cancer, diabetes cardio vascular disorder and other auto immune neurodegenerative diseases. With the ever increasing level of pollution into the environment, there have been significant increase of health risk and other degenerative diseases which may affect very severely.

In the living system free radicals have been classified as oxygen derived (ROS, reactive oxygen species) or nitrogen derived (RNS, reactive nitrogen species). Superoxide (O-2), hydroxyl $(\mathrm{OH})$, hydroperoxyl $\left(\mathrm{HO}_{2}\right)$, peroxyl (ROO), alkoxyl (RO) and nitric oxide (NO), peroxy nitrate (ONOO-), nitrogen dioxide $\left(\mathrm{NO}_{2}\right)$, dinitrogen trioxide $\left(\mathrm{N}_{2} \mathrm{O}_{3}\right)^{2}$. Combination of one free radical with any molecule to neutralize themselves results in the liberation of another free radical which cause a chain reaction resulting in libartion of large number of free radicals which further lead to ageing related disease ${ }^{23,24}$, cancer, arteriosclerosis and coronary heart disease, aging, immune system decline, brain dysfunction.

In human body the major contribution for the free radical is in the form of reactive oxygen species (ROS), which may cause oxidative damage in nuclear DNA which causes mutations and lead to destruction of vital molecular mechanisms, oxidative damage of lipids and proteins also play an important role in aging process. Oxidatively modified proteins are incorrectly folded, instable and assume structures that form aggregates which lead to a number of degenerative human diseases. As the damage is caused at molecular level, ROS leads to a number of age specific diseases 25,26 .
Based upon the mode of action antioxidants can be classified as Enzyme antioxidants (Superoxide dismutases, Catalase, Glutathione peroxidase and Caeruloplasmin), Chain breaking antioxidants (tocopherols, ubiquinol, carotenoids) and Metal binding proteins.

Previous structure-activity relationship (SAR) studies of flavonoids have pointed to the importance of the number and location of the phenolic $\mathrm{OH}$ groups present for the antiradical efficacy. The structural requirement considered to be essential for effective radical scavenging by flavonoids is the presence of an electron rich centre which may contribute to the radical scavenging activity. The C2-C3 double bond conjugated with a 4-keto group, which is responsible for electron delocalization from the $B$ ring, enhances further the radical-scavenging capacity, and saturation of the C2-C3-double bond is believed to cause a loss of activity potential. Structure activity relationship studies of flavonoids have pointed to the importance of various electron donor and receptor sites available which may have a direct effect on the radical scavenging activity associated with molecules.

The structural requirements considered to be essential for effective radical scavenging activity of flavonoids is presence of various groups in conjugation with $\mathrm{C} 2-\mathrm{C} 3$ pie electrons which may have significant contribution for electron delocalization. Substitution of various group on the A-ring of chromone nucleus may lead to a significant change in their activity behaviour towards the free radical generated in the system.

Flavonoid antioxidants function as scavengers of free radicals by rapid donation of a hydrogen atom to radicals. DPPH is a free radical compound and it has been widely used to test the free radical scavenging ability of flavonoids ${ }^{27}$.

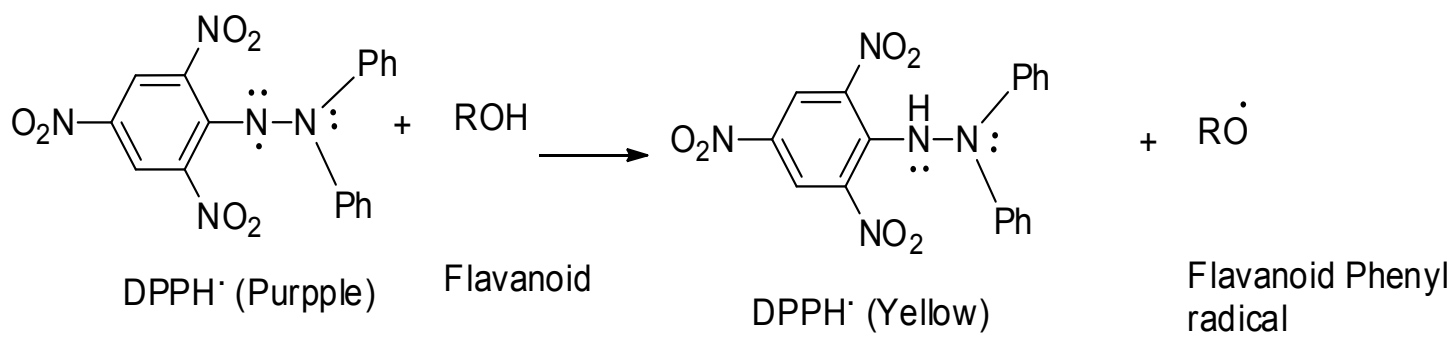

Fig. 1. Scavenging of DPPH• (free radical) by a flavonoid (free radical scavenger) 
The electron donation ability of natural products can be measured by the action on purple coloured 2,2'-diphenyl-1- picrylhydrazyl radical (DPPH) solution and observation of bleaching action on the $\mathrm{DPPH}^{28}$. The method is based on scavenging of DPPH through the addition of a radical species or antioxidant that decolourizes the DPPH solution. The degree of colour change is proportional to the concentration and potency of the antioxidants. A large decrease in the absorbance of the reaction mixture indicates significant free radical scavenging activity of the compound under test ${ }^{29}$.

\section{MATERIALS AND METHODS}

The present investigation is aimed around the synthesis of molecules involving Chromone nucleus (an important member of flavone family) and semicarbazone under catalytic conditions so as to yield a compound which possesses the basic<smiles>[R]c1ccc2occ(C=O)c(=O)c2c1</smiles>

4

\section{Scheme- 1}

2-((4-oxo-4H-chromen-3-yl)methylene)hydrazine -carboxamide (5a)

Yellow solid, $80 \%$; m. p. $176-178^{\circ} \mathrm{C}$, I.R data (KBr) N-H 3431, C=O 1664, C=N 1545, C=S 1085, C-N $1311 \mathrm{~cm}^{-1},{ }^{1} \mathrm{H}$ NMR (300 MHz, DMSO- $\left.{ }_{\mathrm{d}}\right): \delta$ 7.20(s, $1 \mathrm{H}, \mathrm{NH}), 7.53(\mathrm{~s}, 1 \mathrm{H}, \mathrm{CH}), 7.45-7.72(\mathrm{~m}, 3 \mathrm{H}$, Ar-H), 7.95-8.23(m, 2H, Ar-H).

\section{2-((6-methyl-4-oxo-4H-chromen-3-yl)methylene) hydrazinecarboxamide (5b)}

Yellow solid, $60 \%$; m. p. $180-182^{\circ} \mathrm{C}$, I.R data (KBr) N-H 3431, C=O 1664, C=N 1545, C=S 1085, $\mathrm{C}-\mathrm{N} 1311 \mathrm{~cm}^{-1},{ }^{1} \mathrm{H}$ NMR (300 MHz, DMSO- ${ }_{\mathrm{d} 6}$ ): $\delta$ 7.20(s, $1 \mathrm{H}, \mathrm{NH}), 7.53(\mathrm{~s}, 1 \mathrm{H}, \mathrm{CH}), 7.45-7.72(\mathrm{~m}, 2 \mathrm{H}$, Ar-H), 7.95-8.23(m, 2H, Ar-H).

\section{2-((6-chloro-4-oxo-4H-chromen-3-yl)methylene) hydrazinecarboxamide (5c)}

Pale yellow solid, $75 \%$; m. p. $174-176{ }^{\circ} \mathrm{C}$, I.R data $(\mathrm{KBr}) \mathrm{N}-\mathrm{H} 3431, \mathrm{C}=\mathrm{O} 1664, \mathrm{C}=\mathrm{N} 1545, \mathrm{C}=\mathrm{S}$ 1085, C-N $1311 \mathrm{~cm}^{-1},{ }^{1} \mathrm{H}$ NMR (300 MHz, DMSO- ${ }_{\mathrm{d} 6}$ ): characteristic of flavone nucleus and have the additional sites available for the interaction which may enhance the availability of $\pi$-electron around the chromone nucleus.

In order to investigate the radical scavenging activity, synthesis was carried out by taking differently substituted chromones with semicarbazone, the product so obtained was subjected to study for the antioxidant behaviour.

A typical synthesis was carried out by mixing respective 3-formylchromone derivative (1.0 eq) with semcarbazone (1.2eq) in anhydrous methanol. Contents were stirred till the completion of reaction (TLC). After the completion of reaction methanol was evaporated under reduced pressure to afford solid mass which was triturated with diethyl ether to afford the pure product, the product so obtained was used for further investigations as an anti-oxidant.

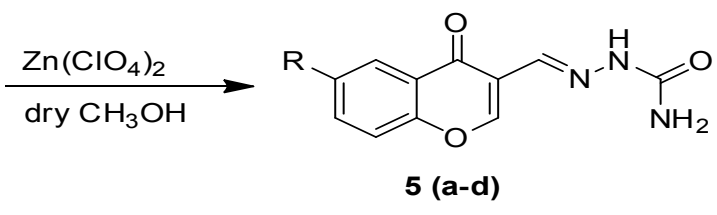

$$
\begin{array}{ll}
\text { a } & \mathrm{R}=\mathrm{H} \\
\text { b } & \mathrm{R}=\mathrm{CH}_{3} \\
\text { c } & \mathrm{R}=\mathrm{Cl} \\
\text { d } & \mathrm{R}=\mathrm{F} \\
\text { e } & \mathrm{R}=\mathrm{Br}
\end{array}
$$

$\delta 7.20(\mathrm{~s}, 1 \mathrm{H}, \mathrm{NH}), 7.53(\mathrm{~s}, 1 \mathrm{H}, \mathrm{CH}), 7.43-7.74(\mathrm{~m}, 2 \mathrm{H}$, Ar-H), 7.95-8.23(m, 2H, Ar-H).

\section{2-((6-fluoro-4-oxo-4H-chromen-3-yl)methylene) hydrazinecarboxamide (5d)}

Light yellow solid, $70 \%$; m. p. $180-182^{\circ} \mathrm{C}$, I.R data (KBr) N-H 3431, C=O 1664, C=N 1545, C=S 1085, C-N $1311 \mathrm{~cm}^{-1},{ }^{1} \mathrm{H}$ NMR (300 MHz, DMSO- ${ }_{\mathrm{d} 6}$ ): $\delta 7.20(\mathrm{~s}, 1 \mathrm{H}, \mathrm{NH}), 7.53(\mathrm{~s}, 1 \mathrm{H}, \mathrm{CH}), 7.43-7.72(\mathrm{~m}, 2 \mathrm{H}$, Ar-H), 7.93-8.22(m, 2H, Ar-H).

\section{2-((6-methyl-4-oxo-4H-chromen-3-yl)methylene) hydrazinecarboxamide (5e)}

Yellow solid, $70 \%$; m. p. 183-1850C, I.R data $(\mathrm{KBr}) \mathrm{N}-\mathrm{H}$ 3431, $\mathrm{C}=\mathrm{O} 1664, \mathrm{C}=\mathrm{N} 1545, \mathrm{C}=\mathrm{S}$ 1085, C-N $1311 \mathrm{~cm}^{-1},{ }^{1} \mathrm{H}$ NMR (300 MHz, DMSO- ${ }_{\mathrm{d} 6}$ ): $\delta 7.20(\mathrm{~s}, 1 \mathrm{H}, \mathrm{NH}), 7.53(\mathrm{~s}, 1 \mathrm{H}, \mathrm{CH}), 7.41-7.73(\mathrm{~m}, 2 \mathrm{H}$, Ar-H), 7.93-8.22(m, 2H, Ar-H).

The respective Chromone derivative so synthesized was used to prepare a stock solution 
of known concentration by dissolving in DMSO and further required dilutions were made using stock solution and diluted with DMSO.

After the dilution each of the compound solution was mixed with standard DPPH solution and was allowed to stand for $30 \mathrm{~min}$. and a change in the absorption behaviour of the chromone derivative solution was observed by measuring the change in absorption behaviour in UV-spectrum (UV-spectrum recorded on Schimadzu UV-1800S double beam spectrophotometer using glass cuvette) and scavenging activity of each of the compound was calculated by

DPPH scavenged $(\%)=\left(A_{\text {con }}-A_{\text {test }}\right) / A_{\text {con }}{ }^{*} 100$ $A_{c o n}-$ is the absorbance of the control reaction.

$A_{\text {test }}$ - is the absorbance in the presence of the sample.

The carry over the complete investigations the compounds were diluted to different concentrations $(10,20,50$ and $100 \mathrm{ppm})$ and studies were continued with observation in change of absorption behaviour with change in concentration.

\section{RESULTS AND DISCUSSION}

The Chromone derivatives show a significant radical scavenging activity at a concentration of $20 \mathrm{ppm}$ and $50 \mathrm{ppm}$ a further increase in the concentration did not yielded in significant change absorption behaviour. In the absorption spectrum recorded a significant change in the absorption behaviour is observed in the range of $480-574 \mathrm{~nm}$, the absorption maxima obtained due to presence of DPPH in the solution, however with the induction of chromone molecules in their respective solutions it shows a significant change in the absorption which varies with change in substituents $(5 a-d)$ on the periphery of chromone ring structure. The decrease in the absorption behaviour corresponds to the radical scavenging activity of the chromone derivatives, which is also evident in the calculation of percentage inhibition of radical activity upon mixing with DPPH. These studies also show a significant role of substituents present on the ring at C-6 position of Chromone ring, the presence of more electronegative atom leads to increase in the radical scavenging activity and in the absence of any substituent the activity was significantly lowered indicating a clear role of electronegative atoms present.

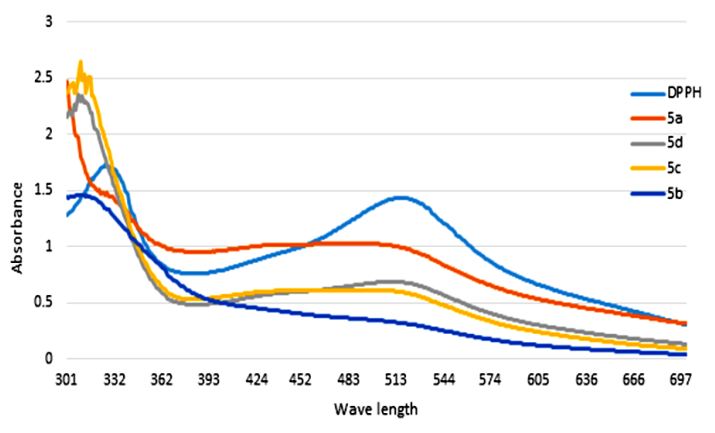

Fig. 2. Relative absorption behaviour of various chromone derivatives $(5 a-d)$

Table 1: Data for radical scavenging activity of various chromone derivatives at 10,20 , 50 and $100 \mathrm{ppm}$

\begin{tabular}{lcccc}
\hline \multicolumn{5}{c}{ \% scavenging } \\
\hline entry & $10 p p m$ & $20 p p m$ & $50 p p m$ & $100 p p m$ \\
$5 \mathrm{a}$ & 49.25 & 58.19 & 73.77 & 89.93 \\
$5 \mathrm{~b}$ & 53.52 & 60.81 & 76.98 & 90.96 \\
$5 \mathrm{c}$ & 78.45 & 86.56 & 89.46 & 91.86 \\
$5 \mathrm{~d}$ & 86.17 & 86.67 & 88.49 & 94.93 \\
$5 \mathrm{e}$ & 63.36 & 64.35 & 67.44 & 70.25 \\
Ascorbic Acid & 69.4 & 75.24 & 83.37 & 91.29 \\
\hline
\end{tabular}

In order to establish the relative radical inhibition activity, all the absorption behaviour of all the compounds was recorded with comparison to the standard ascorbic acid solution which shows a very significant and comparable absorption behaviour indicating the same type and role of chromone derivatives as of ascorbic acid.

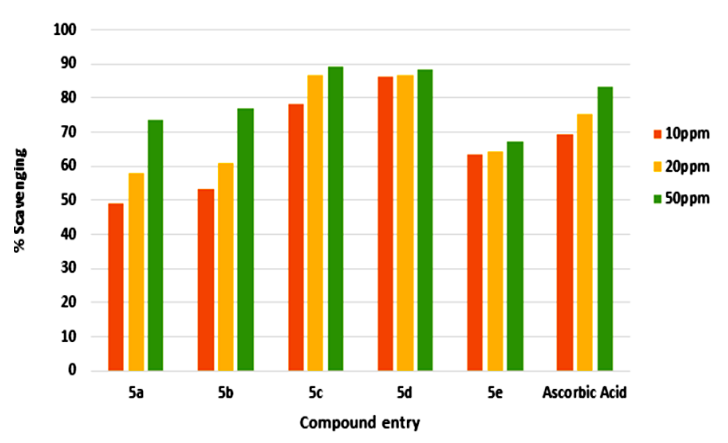

Fig. 3. Relative absorption of the compounds (5a-e) at different concentrations with respect to ascorbic acid

Herein the substituent with more electro negative atoms fluorine and chlorine have shown the similar radical scavenging activity, while in the absence of electronegative group this leads to the decrease in the activity. 


\section{CONCLUSION}

The present investigation provides an insight into radical scavenging activity of chromone derivatives where role and contribution of each of the substituent at C- 6 position of chromone ring can be studied. Presence an electronegative group at C- 6 of chromone nucleus significantly enhances the activity, while in the absence of electronegative group the activity is reduced and presence of electron donating group tends to lower down the radical scavenging activity. A detailed analysis of the results suggest that these derivatives are of significant importance which play a role as an antioxidant. The present investigation leads to the synthesis and study of these compounds which could be available in the nature but can be easily synthesized in high quantities and it provide a further lead into the in-depth mechanistic studies for their role at molecular levels.

\section{ACKNOWLEDGEMENT}

The financial support along with the instrumentation facility provided by the Lovely Professional University to carryout research work is gratefully acknowledged.

\section{REFERENCES}

1. V. Lobo, A. Phatak, and N. Chandra, Pharmacogn., 2010, 4, 118-126.

2. Rangappa S. Keri, Srinivasa Budagumpi, Ranjith Krishna Pai, R. Geetha Balakrishna, European Journal of Medical Chemistry. 2014, 78, 340-374.

3. Pietta, P.-G. J. Nat. Prod., 2000, 63, 1035.

4. Growless, A., Cardellina II J.H., Boyd, M.R., J. Nat. Prod., 2000, 63, 1537.

5. Yenesew, A., Induli, M., Derese, S., Midiwo, J.O., Heydenreich, M., Peter, M.G., Akala, H., Wangui, J., Liyala, P. Waters, N.C. Phytochemistry., 2004, 65, 3029.

6. Du, J., He, Z.-D., Jiang. R.-W., Ye, W.-C., Xu, H.-X., But, P.-H. Phytochemistry., 2003, 62, 1235.

7. Khan, I.A., Avery, M.A., Burandt, C.L., Goins, D.K., Mikell, J.R., Nash, T.E., Azadegan, A., Walker, L.A. J. Nat. Prod., 2000, 63, 1414.

8. Falcao, M.J.C., Pouliquem, Y.M.B., Lina, M.A.S., Gramosa, M.V., Coste-Lotufo, L.V., Militao, G.C.G., Pessoa, C., De Moraes, M.O., Silveria, E.R. J. Nat. Prod., 2005, 68, 423.

9. Walker, E.H., Pacold, M.E., Perisic, O., Stephens, L., Hawkins, P.T., Wymann, M.P., Williams, R.L. Molecular Cell., 2000, 6, 909.

10. Stefanic-Petek, A., Krbavcic A., Solmajer, T. Croatica Chemica Acta., 2002, 75, 517.

11. Drewes, S.E., Horn, M.H., Munro, O.-Q., Dhlamini, J.T.B., Meyer, J. J. M., Rakuambo, N. C. Phytochemistry., 2002, 59, 739.

12. Ravasi, S., Capra, V., Panigalli, T., Rovati, G.E., Nicosia, S. Biochem. Pharmacol., 2002, 63, 1537.

13. Fujimoto, H., Nozowa, M., Okuyama, E., Ishibashi, M. Chem. Pharm. Bull., 2003, 51, 247.

14. Moro, S., Van Rhee, A.M., Sandres, L.H., Jacobson, K. A. J. Med. Chem., 1998, 41, 46.

15. Mazzei, M., Balbi, A., Roma, G., Di Braccio, M., Leoncini, G., Buzzi E., Maresca, M. Eur. J. Med. Chem., 1988, 23, 587.

16. Gloer, J.B., Wang, H.-J., Scott, J.A., Malloch, D. Tetrahedron Lett., 1995, 36, 5847.

17. Armani, G., Armani, E., Ghirarda, S.,
Delcanale, M., Civelli, M., Caruso, P.L., Galbiati, E., Lipreri, M., Rivara, S., Lodola, A., Mor, M. Biorg. Med. Chem., 2004, 12, 3763.

18. Gross, A., Borcherding, D.R., Friedrich, D., Sabol, J.S. Tetrahedron Lett., 2001, 42, 1631 (b) Mukherjee, A.K., basu, S., Sarkar, N., Ghosh, A.C. Curr. Med. Chem., 2001, 1467.

19. Bolos, J., Anglada, L., Gubert, S., Planas, J. M., Augut, J., Princep, M. A., Fuente, De la, Sacristan, A., Ortiz, J.A. J. Med. Chem., 1998, 41, 5402.

20. Larget, R., Lockhart, B., Renard, P., Largeron, M. Bioorg. Med. Chem. Lett., 2000, 10, 835.

21. (a) Hadjeri, M., Barbier, M., Ronot, X., Mariotte, A.-M., Boumendjel, A., Boutonnat, J. J. Med. Chem., 2003, 46, 2125.

22. Rangappa S. Keri, Srinivasa Budagumpi, Ranjith Krishna Pai, R. Geetha Balakrishna, European Journal of Medical Chemistry., 2014, 78, 340-374.

23. P K Basniwal, M Suthar, G S Rathore, R Gupta, V Kumar, A Pareek and D Jain, Natural Product Radiance., 2009, 8, 483-487.

24. Abdul Qaiyum Ansari, Syed Abrar Ahmed, M.A. Waheed and Sayyed Juned, European Journal of Experimental Biology., 2013, 3, 502-507.

25. IS Young, JV Woodside, J Clin Pathol., 2001, 54, 176-186.

26. Michael Antolovich, Paul D. Prenzler, Emilios Patsalides, Suzanne McDonald and Kevin Robards, Analyst., 2002, 127, 183-198.

27. Dragan Ami, Dusanka Davidovi-Amic, Drago Beslo and Nenad Trinajsti, Croatica Chemica Acta., 2003, 76, 55-61.

28. Nunes P.X., Silva S.F., Guedes R.J., Almeida $S$. Biological oxidations and antioxidant activity of natural products, Phytochemicals as nutraceuticals - Global Approaches to Their Role in Nutrition and Health., 2012.

29. Krishnaiah D, Sarbatly R, Nithyanandam RR. Food Bioprod Process., 2011, 89, 217-233. 